\title{
Analyzing the technical efficiency of health systems in Asian countries: What Myanmar can learn from Bangladesh and Sri Lanka.
}

\section{Zin Mar Win}

Umea Universitet Medicinska fakulteten

Curt Löfgren ( $\nabla$ curt.lofgren@umu.se )

Umea Universitet Medicinska fakulteten https://orcid.org/0000-0002-5348-7698

\section{Research article}

Keywords: data envelopment analysis, health care cost, efficiency, Myanmar, Asian countries

Posted Date: July 29th, 2020

DOI: https://doi.org/10.21203/rs.3.rs-21181/v2

License: (c) (1) This work is licensed under a Creative Commons Attribution 4.0 International License.

Read Full License 


\section{Abstract}

Background: Advancements in medicine leads, among other things, to increasing life expectancy and quality of life. However, at the same time, health care costs are increasing, and this may not be sustainable in the future. Governments and health care organizations need to implement efficiency measures in order to maximize health outcomes within available resources. This study aims to compare the technical efficiency of health systems in middle-income Asian countries, and to identify "efficient peers" for each "inefficient country": in particular for Myanmar.

Methods: A data envelopment analysis (DEA) variable returns to scale output-oriented model was used to evaluate technical efficiency in middle-income Asian countries. The input variables were current health expenditure per capita, the density of doctors, and the density of nurses and midwifery personnel. The output variables were health adjusted life expectancy (HALE) and the infant mortality rate (IMR). Myanmar may learn how to improve efficiency of its health care system through studying its efficient peers from DEA results. A review of relevant English language literature was used as a basis for informing a comparative analysis of the health systems of Myanmar and its efficient peers: Bangladesh and Sri Lanka.

Results: Among the twenty-eight middle-income Asian countries studied, 39.3\% of countries were technically efficient. Myanmar is one of the inefficient countries, and it should look at the health systems of its efficient peers, Bangladesh and Sri Lanka, to make its health system technically more efficient.

Conclusions: The results of this study suggested that countries with inefficient health systems can improve their health outcomes without increasing their health care resources. As DEA measures efficiency only, future studies should take into account equity to assess comprehensive health system performance.

\section{Background}

Advancements in medicine help people live longer. Life expectancy is increasing. According to data published by World Health Organization (WHO), life expectancy increased by 5.5 years between 2000 and 2016 globally (1). However, at the same time, health care is becoming more expensive. Between 2000 and 2016, health expenditure per capita rose from US\$ 15 to 33 in low-income countries, from US\$ 22 to 79 in lower middle- income countries, from US\$ 103 to 455 in upper middle-income countries, and from US\$ 2430 to 5180 in high-income countries (2). As such, increasing health care costs is a major challenge for almost every country in the world.

The significant amounts of health care spending are wasted worldwide. The WHO estimates that globally $20 \%-40 \%$ of total health spending, equivalent to a current monetary value around 1.5 trillion, is being wasted every year due to health system inefficiency (5). Inefficient health systems negatively impact on population health, which in turn affects productivity, education, and human welfare $(3,4)$. According to 2010 estimates from the Organization for Economic Cooperation and Development (OECD), life 
expectancy at birth would increase by more than two years without increasing health care spending, if the health care systems of all OECD countries performed at their maximum levels (6). These issues highlight the need for greater efficiency in health system.

In general, countries that spend more on health have higher life expectancies (7). For example, an average life expectancy at birth for high-income countries was 80.6 years whereas 62.9 years for low-income countries in 2016 (8). However, countries that spend most on their health care do not necessarily have best health outcomes, best exemplified by the United States (7). Interestingly, countries with differing proportions of health care expenditure can have similar health outcomes. For instance, life expectancy in Uruguay and that in Paraguay are the same (75 year), but Uruguay's health expenditure per capita is four times higher than Paraguay's $(6,9,10)$. Even though there are other determinants of health, there clearly is scope to improve the effectiveness of health care spending within countries (6).

Efficiency in the health sector means achieving maximum health within available resources or using minimum resources for the given level of outputs. This is "technical efficiency" in economic terms $(5,11)$. Health care efficiency can be measured at micro level to compare performance in diagnostic and therapeutic procedures between departments and hospitals etc., $(11,12)$ at meso-level to evaluate organizational efficiency (13), and at macro level to assess health systems between countries $(3,14,15)$. Cross- country comparisons of health system performance can provide opportunities to identify whether countries' health systems are performing efficiently, and to take appropriate actions to improve efficiencies in under-performing countries (16).

In terms of health care spending, Asian countries spend much less than OECD countries. Current health expenditure (CHE), expressed as percentage of gross domestic product (GDP), for East Asia and the Pacific Region was 6.6\% and that in the South Asia Region was 3.6\% in 2016. In contrast, 2016 CHE for OECD countries was $12.6 \%$ (17). In addition, out-of-pocket payments (OOPs) as a percentage of CHE are very high in some Asian countries; OOPs were more than $70 \%$ of $\mathrm{CHE}$ in Myanmar and Bangladesh in 2016 (18). High OOPs are strongly correlated with catastrophic health expenditure and impoverishment and can exacerbate poverty $(19,20)$. Moreover, South East Asian region countries are now facing a triple burden of diseases: communicable diseases, non-communicable diseases, and injuries (21). All these factors demand efficient use of health care resources, especially in resource limited Asian countries, in order to improve health of their populations.

Some previous studies have analysed health system efficiency in $\operatorname{OECD}$ countries $(3,14,22)$, but few have compared health system efficiency in Asian countries (15). To our knowledge, no studies have as yet undertaken comparative analysis of the health systems of inefficient Asian countries with the purpose of benchmarking so that inefficient countries might adopt best practices with regard to improving efficiency.

This study includes ten members of the Association of Southeast Asian Nations (ASEAN) (Brunei, Cambodia, Indonesia, Laos, Malaysia, Myanmar, the Philippines, Singapore, Thailand, and Vietnam) together with three neighbouring countries of Myanmar (Bangladesh, China, and India). The aim is to 
compare the technical efficiency of health systems in Asian countries and to identify "efficient peers" for each of the "inefficient" countries.

\section{Methods}

Data Envelopment Analysis (DEA)

DEA is one of the most widely used methods to measure the technical efficiency of operating units (called decision making units, $\mathrm{DMU}$ ). It is a non-parametric, linear programming technique that measures the relative technical efficiency of several decision-making units by calculating the ratio of the weighted sum of outputs to the weighted sum of inputs. Stating it in algebraic terms, given $n$ outputs and $m$ inputs:

$$
E_{0}=\frac{\sum_{r=1}^{n} u_{r} * y_{r 0}}{\sum_{i=1}^{m} v_{i} * x_{i 0}}
$$

where $u_{r}=$ weight attached to output $r, y_{r o}=$ quantity of output $r$ produced by unit $o ; v_{i}=$ weight attached to input $i, x_{i 0}=$ quantity of input $i$ produced by unit $o ; E_{0}=$ technical efficiency of unit $o$ (23).

The efficiency frontier is plotted based on the combinations of inputs and outputs of the best performing DMUs and the efficiency of each other unit can be measured by comparing it with an identified frontier of efficiency. The efficiency ratio ranges from zero to one, with the efficiency frontier being scored $1(100 \%)$ and the inefficient units falling below the frontier scored less than 1 (0-99\%). DMUs located on the frontier are known as "benchmarks or peers". These are the best practice examples which allow comparison with less efficient DMUs. DEA is also considered as a powerful benchmarking technique (24).

The DEA method was originally introduced by Charnes, Cooper, and Rhodes in 1978 assuming constant returns to scale (CRS). It should be used when all DMUs are operating at an optimal scale. In 1984, Banker, Charnes, and Cooper developed a second DEA model assuming variable returns to scale (VRS). This is appropriate when DMUs are not operating at an optimal scale, i.e. DMUs facing imperfect competition, government regulations, etc. Increasing returns to scale (or economies of scale) is a situation where changes in input of $1 \%$ results in greater than $1 \%$ changes in output. Conversely, decreasing returns to scale (or diseconomies of scale) refers to a situation where changes in input of $1 \%$ results in less than $1 \%$ changes in output. The DEA model can be input or output oriented. An outputoriented DEA model maximizes output for a given level of input, whereas, an input-oriented DEA minimizes input for a given level of output (24). Figure 1 shows both the CRS and VRS efficient frontiers on the same graph. 
Figure 1. B is both CRS and VRS efficient. A and E are VRS efficient but not CRS efficient. C and D are both CRS and VRS inefficient.

To measure health system efficiency of middle-income Asian countries, we use DEA because it can deal with multiple inputs and outputs that are measured in different units and their relative values are unknown. It is especially useful to measure efficiency of complex systems like health care systems. This study uses variable returns to scale, an output-oriented model. Variable returns to scale are used because the selected variables are ratios and the health care systems in the studied Asian countries (DMUs) differ in terms of health financing policies and socio-economic characteristics $(23,24)$. An output-oriented model is used as most of the health system objectives refer to maximizing health outcomes by using available resources as efficient as possible. Moreover, inputs such as health expenditure and health care professionals are already assigned, so that it would be inappropriate to advise to reduce health care inputs by using an input-oriented model.

\section{Data and Variables}

Data were collected for the year 2016 from WHO Global Health Expenditure Database and WHO Global Health Observatory Data Repository (18,25-28). Where 2016 data were not available, the closest year data were used. WHO data are comparable across countries which is crucial for DEA. The WHO uses the System of Health Accounts (SHA 2011) framework to provide comparable national health expenditure statistics internationally $(18,29)$.

For the analysis, it is important that the selected health resource inputs have significant impact on the selected outputs. Three selected input variables are current health expenditure per capita in international dollars (Int\$), density of doctors, and density of nursing and midwifery personnel for twenty-eight Asian countries $(18,25,26)$. The output variables, HALE and infant mortality rate (IMR) were used in the analysis $(27,28)$. The IMR was converted to the infant survival rate (ISR) for consistency with the DEA assumption that more output is better. The ISR is 1-IMR/1000 (30). The selection of three inputs and two outputs meets the DEA model requirement in that the number of decision- making units or countries $(n=28)$ exceeds three times the number of input and output variables (24).

Statistical Analysis

STATA 16.0 was used to perform the DEA. The data set included input and output variables for selected Asian countries. First, the countries were named "dmu"- decision making units. The DEA program was run by entering input and output variables. For the analysis reported in this paper, variable returns to scalerts(vrs) and output-oriented model-ort(out)- options were chosen.

\section{Comparative Analysis}

Information on the health systems in Myanmar and its benchmark countries, Bangladesh and Sri Lanka, was extracted from the published scientific literature in online databases, PubMed and Google Scholar 
etc. Search terms are "health system in Bangladesh", "health system in Myanmar", "health system in Sri Lanka" and "health system changes in Asia".

\section{Results}

\section{DEA Results}

The descriptive statistics of the input and output variables for twenty-eight Asian countries are shown in Table 1. Bangladesh has the minimum value of CHE per capita (Int\$89.00), Cambodia has the lowest number of doctors (1.93) and Jordan has the lowest nursing and midwifery personnel (2.08). On the other hand, Iran spend the highest CHE per capita (Int\$ 1712.00) and the maximum number of doctors (59.97) and nursing and midwifery (112.80) are found in Georgia and Uzbekistan respectively. The HALE (57.7) and ISR (0.9395) are the lowest in Pakistan, while Maldives has the highest HALE (69.8) and Lebanon and Malaysia have the highest ISR (0.9932). The average CHE per capita, density of doctors, density of nursing and midwifery personnel, HALE and ISR are Int\$640.79, 16.94, 31.39, 63.63 and 0.9788 respectively.

The selected countries in this study have similar geographical backgrounds, however, their economic circumstances vary with GDP per capita in 2016 ranging from Int $\$ 3,648$ to Int $\$ 27,731$. Moreover, CHE per capita as percentage of GDP varies between $2 \%$ and $10 \%$. Out-of-pocket expenditure (OOPs) as percentage of $\mathrm{CHE}$ is also ranging from $9 \%$ to $82 \%(18)$.

Table 2 illustrates the DEA results. Eleven out of twenty-eight countries - Bangladesh, Cambodia, China, Jordan, Kyrgyzstan, Lebanon, Malaysia, Maldives, Sri Lanka, Thailand and Vietnam- demonstrated pure technical efficiency. Pakistan was the least efficient country with VRS efficiency score of 0.9636 , meaning that Pakistan could increase output by $3.64 \%$ with existing inputs if they perform at the maximum efficiency. The VRS efficiency scores for the other inefficient countries varied from 0.9648 to 0.9984 , indicating that $0.16 \%$ to $3.52 \%$ of increased output can be achieved without using more inputs.

The last column shows inefficient countries and their peers (composite members) with reference weight given. For each inefficient DMU, the DEA identifies the comparable, closest efficient DMU peers as the best practice examples to improve the performance of inefficient DMUs (12). Reference weight given to each peer corresponds to its relative importance for each peer among composite members. For example, Myanmar's composite countries were formed by Bangladesh (weight 0.44), Cambodia (0.13) and Sri Lanka (0.40). The country should look at best practice of peers associated with the highest weight value so that the role models for Myanmar will be Bangladesh and Sri Lanka for improvement in its health outputs. 
Sensitivity analysis was performed to determine the stability or robustness of the efficiency scores obtained by data envelopment analysis. In this study, we conducted sensitivity analysis by changing a single variable of efficient DMUs while data of other inefficient DMUs remain unchanged. We gradually increased the proportion $(10 \%, 15 \%, 20 \%$ and $25 \%$ increase) of input data (CHE per capita, density of doctors and density of nursing and midwifery personnel) one at a time until efficiency frontier DMUs change. For CHE, efficient DMUs frontier unchanged until 25\% increase where Indonesia (the least inefficient country in original data set) turned out to be efficient. Similarly, gradual increase in proportion of number of nursing and midwifery personnel did not change until $25 \%$ increase where efficiency frontier was made up of Indonesia together with other original efficient DMUs. However, number of doctors is the most sensitive variable and only $15 \%$ increase would cause Indonesia to become an efficient country together with other original efficient countries.

\section{Discussion}

\section{Discussions of DEA results, strengths and weakness}

The findings of this analysis demonstrated that eleven (39.3\%) out of twenty-eight countries were technically efficient and the remaining seventeen inefficient countries could improve $1.28 \%$ (compared to efficient countries in this study) without using more resources. Being the least efficient country, Pakistan had the lowest HALE and the highest IMR. Countries with the highest HALE, Maldives, and lowest IMR, Lebanon and Malaysia, were among the efficient countries and as expected, majority of efficient countries had higher than average HALE and ISR. Although Bangladesh and Cambodia had slightly lower than average HALE and ISR, they were on efficiency frontier because of their very low inputs. This suggests that these countries made good use of their scarce resources to produce good health outcomes.

The findings from a previous study that includes all low-, middle- and high-income Asian countries showed that Bangladesh was the only efficient country belonged to lower middle-income countries and majority of efficient countries; Singapore, Japan and Cyprus, belonged to the high-income countries (15). In our study Bangladesh was also one of the efficient countries, but results were not completely comparable because of the differences in number of countries, inputs and outputs involved.

The DEA's identification of peers provides an important and useful policy information for inefficient countries to reform their health systems. The selected sample in this paper included Asian countries only. Geographic proximity makes it easier for country to relate within their region. An inefficient country could focus more on peer countries with higher reference weights as they are likely to be better role models to emulate their health care policies and practices.

Although DEA is very useful, it has its own limitations. The method cannot measure true efficiency and results can change depending on the number and nature of DMUs selected in the sample. The inefficiency results tend to be underestimated as it is calculated in relation to the efficiency frontier of the sample. For instance, Myanmar's efficiency score 0.9794 does not mean that it could improve only by 
$2.06 \%$. It means that Myanmar could improve $2.06 \%$ compared to the most efficient country in the sample selected.

In this analysis, only CHE per capita, doctor density and nursing and midwifery personnel density were used as inputs. Although other factors outside of health system like education, social class, lifestyle, environmental factors and country policy etc. play an important role in health outcomes, these factors were not taken into account in this study.

\section{Comparative analysis of health systems of Myanmar, Bangladesh and Sri Lanka}

Myanmar should learn successful strategies of health systems from its benchmark countries, Bangladesh and Sri Lanka, to improve efficiency. "A system framework for analysing the efficiency of health care resource use" indicates that health system efficiency can be influenced by a set of policy instruments: financing, provider payment methods, organization and regulation (10). The policy makers should target these instruments to reform their health system to be more efficient. In the following sections, the health systems of three countries are compared and analysed in terms of policy instruments. However, provider payment methods are not used owing to a lack of comparable data.

\section{Financing}

Table 3 describes health financing of Myanmar, Bangladesh and Sri Lanka. Myanmar's current health expenditure is around $5 \%$ of GDP. The majority of CHE comes from OOPs (77\%) and domestic general government health expenditure is only $14 \%$ (18). Health insurance scheme called 'Social Security Scheme (SSS)" for employees is regulated through the Ministry of Labour, Employment and Social Security, but its contribution is negligible (31).

In Bangladesh, current health expenditure is only $2 \%$ of GDP. CHE is mainly made up of OOPs (73\%) and only $16 \%$ are contributed by domestic general government health expenditure (18). In recent years, some non-governmental organizations (NGOs) have piloted health insurance schemes, however, there is no successful health insurance in Bangladesh yet (32).

The CHE of Sri Lanka is around $4 \%$ of GDP. Government health expenditure is the highest ( $43 \%$ of $\mathrm{CHE}$ ) and OOPs is the lowest ( $50 \%$ of $\mathrm{CHE}$ ) among three countries (18). Even though national health insurance scheme has not yet developed, there are a contributory health insurance scheme that covers some publicsector employees, a growing private health insurance industry that covers mostly private sector employees and publicly-financed school health insurance scheme that covers all students, with caps on claims (33). Sri Lanka has introduced tax on sugar sweetened beverages to tackle risk factors for noncommunicable diseases (NCD) (34). 
Myanmar's health care system has evolved with changing political situation and growing demand from people. Although both public and private sectors are involved in health care financing and provision, the Ministry of Health $(\mathrm{MOH})$ remains the major provider of comprehensive health care services providing all aspects of health care. The $\mathrm{MOH}$ supervises both administrative and technical functions of state/region health departments, district health departments and township health departments (35). The private, for profit, sector has expanded rapidly especially in major cities and it is estimated to provide $75 \%-80 \%$ of ambulatory care (31).

International aid agencies used to have difficulty in engaging Myanmar Government under the isolated military regime, but this is changing under the quasi-civilian government (36). At present, communitybased organizations, local and international non-governmental organizations are increasingly involved to deliver health care services across the country. However, one review article about 'Healthcare in Myanmar' suggests donors to discuss the health care systems more openly to reduce overlapping functions and to avoid duplicated donations (31).

The Bangladesh health system is made up of five-layers. The lowest level is village health facility with community clinics, the second layer is Union health and Family Welfare Centre, the next level is the Upazila Health Complex and the fourth level is the district hospital with theatre facilities. Medical colleges and post-graduate institutes offering a wide range of health services are at the top of the health system (37).

The government of Bangladesh accommodates many stakeholders and explicitly works together with the private sectors, local and international non-governmental organizations (NGOs) and informal providers. Extensive community programs are very successful in reaching all households in community and implementing health programs such as maternal and child health and family planning programs etc. Prowomen development programs in economy, education as well as health sectors shown to improve health of the population (38).

Sri Lanka's mixed health care system consists of a tax-funded public sector and a fee-for-service private sector. The public sector provides $95 \%$ of inpatient care and approximately $50 \%$ of outpatient care. The central Ministry is responsible for providing technical guidance and policy making, medical education, research and development, management of national facilities and purchasing and distribution of drugs and medical supply. The nine Provincial Directors of Health are responsible for the management and implementation of health services in the provinces $(33,39)$.

Systematic investment and a firm foundation of primary health care have resulted in the country's many health achievements like reaching most of the targets of Millennium Development Goals (MDGs), reducing maternal and neonatal mortality and eradicating communicable diseases such as malaria, tetanus and filariasis etc. Therefore, country's primary health care system has been recognized internationally as a low-cost high-impact system $(34,40)$. Sri Lanka's MOH cooperate with other 
government agencies, development partners, academia and non-governmental organizations in implementing its activities, so that a multitude of partners are active in the health sector in Sri Lanka (34).

\section{Regulation}

In terms of regulations and policy, Myanmar has regulations for licensing medical professionals, the national essential medicine policy, the food and drug administration regulations and national health plan every five years but there are few resources and limited capacity to implement them (41).

The government of Bangladesh has established professional regulatory and statutory bodies such as the Bangladesh Medical and Dental Council and Pharmacy council, etc. The National Drug Policy was updated in 2016 to ensure the access to the essential medicines. The Health Care Financing Strategy 2012-2032 was developed aiming to increase funding to reduce personal expenditure on healthcare services and to protect financial risk (37).

Sri Lanka has regulations for essential drugs and drug development, medical doctors and nurses to benefit people. Health master plan 2007-2016 was set out to rationalize primary health-care delivery structure. The national policy and strategic framework for prevention and control of non-communicable diseases was finalized in 2010 to highlight the strategy on health delivery organization change. National health policy 2016-2025 was guided by principles of people-centered care, equity, quality of services and financial protection $(33,40)$.

\section{What Myanmar can learn from Bangladesh and Sri Lanka}

\section{From Bangladesh}

Bangladesh has been recognized as an example of "good health at low cost" and praised for exceptional health achievements (42).

First thing that Myanmar should learn from Bangladesh is its extensive community-based health service delivery system. It reached almost all the households in rural areas and achieved high coverage. For decades, both government and NGOs use large-scale community-based health workers to address the shortage of human resources in health sectors. One successful tuberculosis (TB) community program (more than $90 \%$ cure rate) was already adopted by South Africa for treatment of TB and Human Immunodeficiency Virus (HIV) (43).

Another thing to learn is Bangladesh government's willingness to create an environment for pluralistic health system. Government of Bangladesh has partnered with NGOs, private sectors, informal providers and international donors etc., to address limitation of health care resources in government in order to improve health outcomes of population (43). 
Last but not the least, Myanmar should look at how women empowerment in education, economic as well as in health sectors make impressive achievement in Bangladesh's health system. Bangladesh's education policy that favours girls reduced gender inequality and helped achieve almost universal primary education for aged 6-10 years. Grameen's microcredit for poor rural population, especially for women, was well known innovation in economy and was awarded Nobel Peace Prize in 2006 (38). This microcredit program, together with improvement in education, helped increase women empowerment. This, in turn, has positive effect on women decision making power within and beyond their own family including decision making for health of their family members. In health sector itself, women are employed as frontline workers for most community-based programs, and have exceptional achievements (44).

\section{From Sri Lanka}

Among low- or middle-income countries, Sri Lanka health care system has been recognized to achieve good health outcomes, financial protection and low cost. Many countries are praised for achieving two out of three, while few can claim to have done so well as Sri Lanka on all three (45). One important thing Myanmar can learn from Sri Lanka is its firm foundation of primary health care system that accounts for the country's achievements. The public health care system comprises two streams of primary care services: preventive and curative sectors $(33,40)$.

Preventive health sector covers the entire country systematically and have already achieved impressive results in maternal and child health and communicable disease control activities. Preventive service delivery is decentralized to the provincial departments of health led by medical officer of health who is a general practitioner with public health training. Each medical officer of health is supported by a public health team consisting of assistant medical officer of health, public health inspectors, public health nurses and public health midwives. On the other hand, Sri Lanka's government has now been reforming the curative health sector- which is not well organized as preventive one - focusing on the primary care level to address the increasing burden of non-communicable diseases $(33,40)$.

\section{Myanmar}

Myanmar health care system is still weak in above mentioned practices. Therefore, it will be very useful for Myanmar to adopt these approaches: strengthening primary care services, training community-based health workers in rural area, cooperating with donors and restructuring health financing system, in order to reform its health system.

First of all, Myanmar's primary health care system should be strengthened. As a lower middle-income country (LMIC) where there are limited health care resources, strengthening primary health care is the most efficient way to provide good health care at low cost. In fact, investing in primary care which provides prevention, promotion as well as treatment, will achieve good value for money. According to WHO policy note, putting primary care second place to hospital services is one of the challenges for Myanmar health system to achieve universal health coverage (46). Myanmar health system review also 
mentioned that allocating a majority of budget to secondary and tertiary hospital care services at the expense of primary health care could cause detrimental effect on equity (41). This is the evidence of how primary health care is important in a LMIC like Myanmar. Allocating more budget to primary care as well as increasing overall government's financial investment in health will be necessary to strengthen and upgrade primary health care. Moreover, medical officer or general practitioner who run the primary health care should have proper training that Myanmar still lacks.

Myanmar has an inadequate number and uneven distribution of skillful health workers between urban and rural area $(31,46)$. To address this issue, government should work together with NGOs to train and retain local people in order to have sufficient community-based health workers for underserved rural population. In particular, for maternal and child health, women health workers should be prioritized as women are more comfortable to talk about their health issues to women health workers. In addition, women employment can also increase women empowerment from their own income.

As a LMIC, Myanmar government's health expenditure (US\$ 8 per capita for 2016) is far lower than proposed target (more than $5 \%$ of GDP and more than US\$86 per capita) to achieve universal health coverage (47). This means that Myanmar will need help from international aid agencies to address the shortage of health care resources in government. To use the donor's health care resources efficiently and to reduce overlapping donations, Myanmar government should cooperate and discuss openly with international aid agencies and NGOs.

In terms of health financing, neither of these three countries has established health insurance. However, they recognize the need of financial protection and they are now piloting and trying to reorganize their financing strategy. In addition to the practices mentioned above that already proved efficient in Bangladesh and Sri Lanka, Myanmar should now consider financing reform in parallel with its efficient countries. At present, Myanmar government do not have sufficient resources, so that government cannot, realistically, provide health insurance for all citizens. A combination of different insurance models will be the only option that could provide financial protection for the whole population.

Current health insurance scheme, the social security scheme (SSS), providing health insurance for formal workers covers only $1 \%$ of the population. The health care services provided by the SSS do not satisfy the customers for poor health facilities and long reimbursement process. Firstly, that social security scheme should be scaled up and strengthened to cover all formal workers with contributions from both employees and employers. As formal sector employees and their families pay for (as contributions to SSS) the free public health services they currently consume, there will be more free public resources left to the poor.

To cover elderly, poor and vulnerable population, tax-based health insurance should be arranged through direct and indirect tax. One option to be consider for increasing government tax revenue is 'excise tax' - a kind of tax imposed on products that have a negative impact on health like sugar-sweetened beverages, tobacco, alcohol and fossil fuels (48). Such tax can be earmarked to finance health system only. Imposing excise tax can result in healthier population as well as can generate additional revenues. 
For the population who are not eligible for SSS and tax-based insurance scheme, community-based health insurance should be set up. As weak management, technical and financial difficulties are the common problems of community-based health insurance scheme, government and NGOs should provide subsidies, technical and management advice as appropriate to successfully implement communitybased insurance scheme.

\section{Conclusions}

Health system efficiency is crucial to improve health outcomes of populations especially in the current situation of increasing health care costs resulting from aging populations and expensive medical care. Knowing the efficiency of a country's health system provides the opportunity to analyse health systems and to take appropriate actions to improve performance. Our cross-country comparison of health system performance by using DEA provides empirical evidence of the technical efficiency of health systems in middle-income Asian countries. The findings suggest that countries with inefficient health systems can improve their health outcomes without increasing health care resources. Moreover, DEA identifies most comparable benchmark countries for every inefficient country so that inefficient countries can potentially emulate policies and practices of their role models. It will be very beneficial for Myanmar to learn useful practical approaches and policies of its peers, Bangladesh and Sri Lanka, from our comparative analysis of health systems of these countries.

However, efficiency alone is not enough to meet the needs of increasing demand especially in resourceconstrained countries. The amount of resources governments spend on health care is also important to provide basic health care that their citizens need. One paper argues that government health expenditure should be more than $5 \%$ of GDP and more than US\$ 86 per capita in the pursuit of universal health coverage (47). In addition, DEA cannot measure equity of health care. According to the economic theory, a situation where there is pareto efficiency; allocation of resources in which no individual can be made better off without making another individual worse off; there may be no equity (10). Some studies suggest that instead of health gain and health equity as two separate outcomes, combination of these two should be the one combined goal of the health system that we should try to achieve as efficient as possible (49). Another suggestion that is based on the phenomenon called relative income hypothesis is that income inequality is inversely related to health outcomes, meaning that individual living in a more equal income society will have better health status (50). Therefore, targeting at reducing income inequality together with improving health outcomes of a society efficiently will be a way to achieve both efficiency and equity. Future research should be aimed at developing methodologies to measure efficiency and equity together to assess the comprehensive health system performance.

\section{Abbreviations}

AIDS: Acquired Immune Deficiency Syndrome; ASEAN: The Association of Southeast Asian Nations; CHE: Current Health Expenditure; DEA: Data Envelopment Analysis; DMU: Decision Making Units; GDP: Gross Domestic Product; GNI: Gross National Income; HALE: Health Adjusted Life Expectancy; HIV: Human 
Immunodeficiency Virus; IMR: Infant Mortality Rate, INGO: International Non-Governmental Organization; Int\$: International Dollars; ISR: Infant Survival Rate; LE: Life Expectancy; MMR: Maternal Mortality Rate; NGO: Non-Governmental Organization; OECD: Organization for Economic C0-operation and Development; OOPs: Out of Pocket Payments; VAT: Value Added Tax; WHO: World Health Organization.

\section{Declarations}

\section{Ethics approval and consent to participate}

Not applicable

\section{Consent for publication}

Not applicable

\section{Availability of data and materials}

The datasets used and analyzed during the current study are publicly available from World Health Organization (WHO) and World Bank.

\section{Competing Interest}

The authors declare that they have no competing interests.

\section{Funding}

This study was unfunded.

\section{Authors' contributions}

ZMW analyzed the data and drafted the manuscript. CL reviewed the manuscript, provided feedback and approved the final submission.

\section{Acknowledgements}

The authors gratefully acknowledge the Department of Epidemiology and Global Health, Umea University where this study has been conducted. Thanks also to Jennifer Stewart Williams for reviewing and providing comments on the draft version of the manuscript.

\section{References}

1. Kyu HH, Abate D, Abate KH, Abay SM, Abbafati C, Abbasi N, et al. Global, regional, and national disability-adjusted life-years (DALYs) for 359 diseases and injuries and healthy life expectancy (HALE) for 195 countries and territories, 1990-2017: a systematic analysis for the Global Burden of Disease Study 2017. The Lancet. 2018 Nov 10;392(10159):1859-922. 
2. Current health expenditure per capita (current US\$) | Data [Internet]. Washington DC: World Bank; [cited 2019 Apr 9]. Available from: https://data.worldbank.org/indicator/SH.XPD.CHEX.PC.CD

3. Chisholm D, Evans, D. Improving health system efficiency as a means of moving towards universal coverage. Geneva: World Health Organization; p. 34. Report No.: World Health Report (2010).

4. Asandului L, Roman M, Fatulescu P. The Efficiency of Healthcare Systems in Europe: A Data Envelopment Analysis Approach. Procedia Econ Finance. 2014 Jan 1;10:261-8.

5. Growth_Commission_Working_Paper_24_Population_Health_Economic_Growth.pdf [Internet]. [cited 2019 Aug 18]. Available from:

https://siteresources.worldbank.org/EXTPREMNET/Resources/489960-

1338997241035/Growth_Commission_Working_Paper_24_Population_Health_Economic_Growth.pdf

6. OECD 2010, "Health care systems: Getting more value for money." Paris: Organization for Economic Cooperation and Development; 2010. Report No.: OECD Economics Department Policy Notes, No. 2.

7. Link between health spending and life expectancy: US is an outlier [Internet]. Our World in Data. [cited $2019 \mathrm{Jul}$ 10]. Available from: https://ourworldindata.org/the-link-between-life-expectancy-and-healthspending-us-focus

8. Life expectancy at birth, total (years) | Data [Internet]. Washington DC: World Bank; [cited 2019 Aug 12]. Available from: https://data.worldbank.org/indicator/sp.dyn.le00.in

9. OECD. Health at a Glance 2009: OECD Indicators [Internet]. OECD; 2009 [cited 2019 Jul 10]. (Health at a Glance). Available from: https://www.oecd-ilibrary.org/social-issues-migration-health/health-at-aglance-2009_health_glance-2009-en

10. Yip W, Hafez, R. Improving Health System Efficiency. Reforms for improving the efficiency of health systems: lessons from 10 country cases. Health Syst Gov Financ. 2015;35.

11. Nayar P, Ozcan YA. Data Envelopment Analysis Comparison of Hospital Efficiency and Quality. J Med Syst. 2008 Jun 1;32(3):193-9.

12. Malhotra R, Lehrman S, Malhotra DK. Benchmarking Managed Healthcare Companies. In: Lawrence KD, Kleinman G, editors. Applications of Management Science [Internet]. Emerald Group Publishing Limited; 2015 [cited 2019 Mar 29]. p. 203-22. Available from: http://www.emeraldinsight.com/doi/10.1108/S0276-897620140000017014

13. Hernández AR, Sebastián MS. Assessing the technical efficiency of health posts in rural Guatemala: a data envelopment analysis. Glob Health Action [Internet]. 2014 Jan 20 [cited 2019 Apr 13];7. Available from: https://www.ncbi.nlm.nih.gov/pmc/articles/PMC3901389/

14. Retzlaff-Roberts D, Chang CF, Rubin RM. Technical efficiency in the use of health care resources: a comparison of OECD countries. Health Policy Amst Neth. 2004 Jul;69(1):55-72.

15. Ahmed S, Hasan MZ, MacLennan M, Dorin F, Ahmed MW, Hasan MM, et al. Measuring the efficiency of health systems in Asia: a data envelopment analysis. BMJ Open. 2019 Mar 1;9(3):e022155.

16. Investing in health: benchmarking health systems [Internet]. The Nuffield Trust. 2017 [cited 2019 Apr 9]. Available from: https://www.nuffieldtrust.org.uk/resource/investing-in-health-benchmarkinghealth-systems 
17. Current health expenditure (\% of GDP) | Data [Internet]. Washington DC: World Bank; [cited 2019 Apr 9]. Available from: https://data.worldbank.org/indicator/SH.XPD.CHEX.GD.ZS

18. Global Health Expenditure Database [Internet]. [cited 2020 Jul 5]. Available from: https://apps.who.int/nha/database

19. WHO | Out-of-pocket payments, user fees and catastrophic expenditure [Internet]. Geneva: World Health Organization (WHO). [cited 2019 Jul 10]. Available from: http://www.who.int/health_financing/topics/financial-protection/out-of-pocket-payments/en/ 20. van Doorslaer E, O'Donnell O, Rannan-Eliya RP, Somanathan A, Adhikari SR, Garg CC, et al. Effect of payments for health care on poverty estimates in 11 countries in Asia: an analysis of household survey data. Lancet Lond Engl. 2006 Oct 14;368(9544):1357-64.

21. Dhillon PK, Jeemon P, Arora NK, Mathur P, Maskey M, Sukirna RD, et al. Status of epidemiology in the WHO South-East Asia region: burden of disease, determinants of health and epidemiological research, workforce and training capacity. Int J Epidemiol. 2012 Jun;41(3):847-60.

22. Del Rocío Moreno-Enguix M, Gómez-Gallego JC, Gómez Gallego M. Analysis and determination the efficiency of the European health systems. Int J Health Plann Manage. 2018 Jan;33(1):136-54.

23. Hollingsworth B, Smith P. Use of ratios in data envelopment analysis. Appl Econ Lett. 2003 Sep 15;10(11):733-5.

24. Ishizaka A, Nemery P. Multi-Criteria Decision Analysis: Methods and Software. New York: John Wiley \& Sons, Incorporated, Wiley, Wiley-Blackwell; 2013.

25. GHO | By category | Medical doctors [Internet]. WHO. World Health Organization; [cited 2020 May 2]. Available from: https://apps.who.int/gho/data/node.main.HWFGRP_0020?lang=en

26. GHO | By category | Nursing and midwifery personnel [Internet]. WHO. World Health Organization; [cited 2020 May 2]. Available from: https://apps.who.int/gho/data/node.main.HWFGRP_0040? lang=en

27. GHO | By category | Life expectancy and Healthy life expectancy - Data by country [Internet]. WHO. World Health Organization; [cited 2020 May 2]. Available from: https://apps.who.int/gho/data/view.main.SDG2016LEXv?lang=en

28. GHO | By category | Probability of dying per 1000 live births - Data by country [Internet]. Geneva: World Health Organization (WHO). [cited 2019 Oct 13]. Available from: https://apps.who.int/gho/data/view.main.182

29. WHO | Health Accounts [Internet]. WHO. [cited 2019 Dec 2]. Available from: https://www.who.int/health-accounts/en/

30. Hadad S, Hadad Y, Simon-Tuval T. Determinants of healthcare system's efficiency in OECD countries. Eur J Health Econ. 2013 Apr 1;14(2):253-65.

31. Latt NN, Myat Cho S, Htun NMM, Yu Mon Saw, Myint MNHA, Aoki F, et al. Healthcare in Myanmar. Nagoya J Med Sci. 2016 May;78(2):123-34. 
32. Islam A, Biswas T. Health System in Bangladesh: Challenges and Opportunities. Am J Health Res. 2014 Jan 1;2:366.

33. Kumar R. Public-private partnerships for universal health coverage? The future of "free health" in Sri Lanka. Glob Health. 2019 Nov 28;15(1):75.

34. Total expenditure on health: As a percentage of gross domestic product [Internet]. OECD Publishing; 2014 [cited 2019 May 5]. Available from: https://www.oecd-ilibrary.org/social-issues-migrationhealth/total-expenditure-on-health_20758480-table1

35. WHO Country Cooperation Strategy Myanmar 2014-2018. Geneva: World Health Organization; (World Health Organization, Country Office for Myanmar).

36. Risso-Gill I, McKee M, Coker R, Piot P, Legido-Quigley H. Health system strengthening in Myanmar during political reforms: perspectives from international agencies. Health Policy Plan. 2014 Jul 1;29(4):466-74.

37. WHO country cooperation strategy Bangladesh 2014-2017. Geneva: World Health Organization; (World Health Organization, Country Office for Bangladesh).

38. Chowdhury AMR, Bhuiya A, Chowdhury ME, Rasheed S, Hussain Z, Chen LC. The Bangladesh paradox: exceptional health achievement despite economic poverty. The Lancet. 2013 Nov;382(9906):1734-45.

39. Health-Care-Financing-in-Sri-Lanka.pdf [Internet]. [cited 2020 Jul 5]. Available from: https://www.ips.lk/wp-content/uploads/2018/07/Health-Care-Financing-in-Sri-Lanka.pdf

40. Perera S, Nieveras O, Silva P de, Wijesundara C, Pendse R. Accelerating reforms of primary health care towards universal health coverage in Sri Lanka. WHO South-East Asia J Public Health. 2019 Jan 1;8(1):21.

41. The Republic of the Union of Myanmar Health System Review. World Health Organization; 2015.

42. Good Health at Low Cost': 25 years on. What makes a successful health system?: Dina Balabanova, Martin McKee, Anne Mills, editors London: London School of Hygiene \& Tropical Medicine, 2011. Reprod Health Matters. 2012 Jan;20(39):212-4.

43. Das P, Horton R. Bangladesh: innovating for health. The Lancet. 2013 Nov;382(9906):1681-2.

44. El Arifeen S, Christou A, Reichenbach L, Osman FA, Azad K, Islam KS, et al. Community-based approaches and partnerships: innovations in health-service delivery in Bangladesh. The Lancet. 2013 Dec;382(9909):2012-26.

45. Sri-Lanka-Achieving-pro-poor-universal-health-coverage-without-health-financing-reforms.pdf [Internet]. [cited $2020 \mathrm{Jul}$ 5]. Available from: http://documents1.worldbank.org/curated/en/138941516179080537/pdf/Sri-Lanka-Achieving-propoor-universal-health-coverage-without-health-financing-reforms.pdf

46. What are the challenges facing Myanmar in progressing towards Universal Health Coverage? Asia Pacific Observatory on Health Systems \& Policies, Geneva: World Health Organization; 2015. 
47. Ottersen T, Evans DB, Mossialos E, Røttingen J-A. Global health financing towards 2030 and beyond. Health Econ Policy Law. 2017 Apr;12(2):105-11.

48. Health taxes [Internet]. [cited $2020 \mathrm{Jul} 5$ ]. Available from: https://www.who.int/westernpacific/healthtopics/health-taxes

49. Reidpath DD, Olafsdottir AE, Pokhrel S, Allotey P. The fallacy of the equity-efficiency trade off: rethinking the efficient health system. BMC Public Health. 2012 Jun 22;12(Suppl 1):S3.

50. Kawachi I, Kennedy BP. Income inequality and health: pathways and mechanisms. Health Serv Res. 1999 Apr;34(1 Pt 2):215-27.

\section{Tables}

Table 1. Input and output variables of middle-income Asian countries 


\begin{tabular}{|c|c|c|c|c|c|c|c|}
\hline & Countries & $\begin{array}{l}\text { CHE per capita in } \\
\text { international dollar }\end{array}$ & $\begin{array}{c}\text { Doctors per } \\
10,000 \\
\text { population }\end{array}$ & $\begin{array}{c}\text { Nursing and midwifery } \\
\text { personnel per } 10,000 \text { population }\end{array}$ & $\begin{array}{c}\text { Health } \\
\text { adjusted life } \\
\text { years } \\
\end{array}$ & $\begin{array}{c}\text { IMR per } \\
1000 \text { live } \\
\text { births } \\
\end{array}$ & $\begin{array}{c}\mathrm{ISR}=1- \\
\mathrm{IMR} / 1000\end{array}$ \\
\hline 1 & Armenia & 880.00 & 29.14 & 49.54 & 66.30 & 12.20 & 0.9878 \\
\hline 2 & Azerbaijan & 1155.00 & 34.46 & 64.34 & 64.90 & 21.80 & 0.9782 \\
\hline 3 & Bangladesh & 89.00 & 4.97 & 2.64 & 63.30 & 28.00 & 0.9720 \\
\hline 4 & Bhutan & 293.00 & 4.06 & 15.33 & 60.70 & 26.50 & 0.9735 \\
\hline 5 & Cambodia & 229.00 & 1.93 & 7.20 & 60.80 & 26.20 & 0.9738 \\
\hline 6 & China & 763.00 & 22.94 & 24.67 & 68.70 & 8.50 & 0.9915 \\
\hline 7 & Georgia & 799.00 & 59.97 & 40.00 & 64.90 & 9.10 & 0.9909 \\
\hline 8 & India & 233.00 & 7.59 & 14.95 & 59.30 & 33.20 & 0.9668 \\
\hline 9 & Indonesia & 363.00 & 2.74 & 12.99 & 61.70 & 22.60 & 0.9774 \\
\hline 10 & Iran & 1712.00 & 11.53 & 18.91 & 65.40 & 13.30 & 0.9867 \\
\hline 11 & Jordan & 658.00 & 13.95 & 2.08 & 66.40 & 14.80 & 0.9852 \\
\hline 12 & Kazakhstan & 860.00 & 39.80 & 72.94 & 63.40 & 9.80 & 0.9902 \\
\hline 13 & Kyrgyzstan & 234.00 & 22.13 & 59.45 & 63.50 & 18.90 & 0.9811 \\
\hline 14 & Laos & 155.00 & 4.95 & 10.30 & 57.90 & 40.40 & 0.9596 \\
\hline 15 & Lebanon & 1106.00 & 20.12 & 15.72 & 66.10 & 6.80 & 0.9932 \\
\hline 16 & Malaysia & 1038.00 & 15.36 & 33.97 & 66.60 & 6.80 & 0.9932 \\
\hline 17 & Maldives & 1594.00 & 28.86 & 65.73 & 69.80 & 8.10 & 0.9919 \\
\hline 18 & Mongolia & 542.00 & 28.59 & 40.80 & 61.90 & 15.20 & 0.9848 \\
\hline 19 & Myanmar & 273.00 & 6.20 & 10.34 & 58.40 & 39.30 & 0.9607 \\
\hline 20 & Pakistan & 150.00 & 9.62 & 4.87 & 57.70 & 60.50 & 0.9395 \\
\hline 21 & Philippines & 344.00 & 12.72 & 52.74 & 61.70 & 23.40 & 0.9766 \\
\hline 22 & Sri Lanka & 490.00 & 8.93 & 19.48 & 66.80 & 7.00 & 0.9930 \\
\hline 23 & Thailand & 639.00 & 4.45 & 27.72 & 66.80 & 8.60 & 0.9914 \\
\hline 24 & Timor-Leste & 317.00 & 6.95 & 14.82 & 59.20 & 42.00 & 0.9580 \\
\hline 25 & Turkey & 1133.00 & 18.14 & 25.73 & 66.00 & 10.30 & 0.9897 \\
\hline 26 & Turkmenistan & 1119.00 & 22.25 & 44.27 & 61.40 & 41.80 & 0.9582 \\
\hline 27 & Uzbekistan & 417.00 & 23.74 & 112.80 & 64.50 & 21.50 & 0.9785 \\
\hline 28 & Vietnam & 357.00 & 8.28 & 14.46 & 67.50 & 17.20 & 0.9828 \\
\hline & Mean & 640.79 & 16.94 & 31.39 & 63.63 & 21.21 & 0.9788 \\
\hline & Minimum & 89.00 & 1.93 & 2.08 & 57.70 & 6.80 & 0.9395 \\
\hline & Maximum & 1712.00 & 59.97 & 112.80 & 69.80 & 60.50 & 0.9932 \\
\hline
\end{tabular}

$\mathrm{CHE}=$ current health expenditure, $\mathrm{IMR}=$ infant mortality rate, $\mathrm{ISR}=$ infant survival rate

Table 2. Variable returns to scale, output-oriented DEA results with composite members 


\begin{tabular}{|c|c|c|c|c|c|}
\hline 1 & Armenia & 16 & 0.9946 & 0.5379 & $16(0.71), 22(0.29)$ \\
\hline 2 & Azerbaijan & 23 & 0.9849 & 1.5103 & $15(0.98)$ \\
\hline 3 & Bangladesh & 1 & 1 & 0 & - \\
\hline 4 & Bhutan & 17 & 0.9944 & 0.5646 & $3(0.06), 5(0.66), 22(0.28)$ \\
\hline 5 & Cambodia & 1 & 1 & 0 & - \\
\hline 6 & China & 1 & 1 & 0 & - \\
\hline 7 & Georgia & 13 & 0.9978 & 0.2228 & $16(0.56), 22(0.44)$ \\
\hline 8 & India & 22 & 0.9869 & 1.3123 & $3(0.58), 13(0.08), 22(0.33)$ \\
\hline 9 & Indonesia & 12 & 0.9984 & 0.1557 & $5(0.71), 22(0.02), 23(0.27)$ \\
\hline 10 & Iran & 18 & 0.9936 & 0.6392 & $15(0.22), 16(0.02), 22(0.75)$ \\
\hline 11 & Jordan & 1 & 1 & 0 & - \\
\hline 12 & Kazakhstan & 14 & 0.9970 & 0.2955 & $16(0.67), 22(0.32)$ \\
\hline 13 & Kyrgyzstan & 1 & 1 & 0 & - \\
\hline 14 & Laos & 24 & 0.9846 & 1.5404 & $3(0.72), 5(0.15), 22(0.11)$ \\
\hline 15 & Lebanon & 1 & 1 & 0 & - \\
\hline 16 & Malaysia & 1 & 1 & 0 & - \\
\hline 17 & Maldives & 1 & 1 & 0 & - \\
\hline 18 & Mongolia & 19 & 0.9917 & 0.8277 & $16(0.09), 22(0.90)$ \\
\hline 19 & Myanmar & 25 & 0.9794 & 2.0589 & $3(0.44), 5(0.13), 22(0.40)$ \\
\hline 20 & Pakistan & 28 & 0.9636 & 3.6383 & $3(0.82), 11(0.01), 22(0.13)$ \\
\hline 21 & Philippines & 20 & 0.9906 & 0.9388 & $3(0.15), 13(0.33), 22(0.52)$ \\
\hline 22 & Sri Lanka & 1 & 1 & 0 & - \\
\hline 23 & Thailand & 1 & 1 & 0 & - \\
\hline 24 & Timor-Leste & 26 & 0.9740 & 2.6024 & $3(0.38), 5(0.06), 22(0.53)$ \\
\hline 25 & Turkey & 15 & 0.9965 & 0.3524 & $15(0.45), 16(0.55)$ \\
\hline 26 & Turkmenistan & 27 & 0.9648 & 3.5240 & $15(0.96)$ \\
\hline 27 & Uzbekistan & 21 & 0.9888 & 1.1223 & $13(0.28), 22(0.71)$ \\
\hline 28 & Vietnam & 1 & 1 & 0 & - \\
\hline
\end{tabular}

DMUs= decision making units, VRS TE $=$ variable returns to scale technical efficiency, Composite members=a group of comparable, closest efficient peers, Reference weight= weight given to each peer according to its importance among peer group

Table 3. Health care financing in Myanmar, Bangladesh and Sri Lanka 


\begin{tabular}{lccc}
\hline & Myanmar & Bangladesh & Sri Lanka \\
\hline CHE as \% of GDP & $5 \%$ & $2 \%$ & $4 \%$ \\
\hline Government health expenditure as \% of CHE & $14 \%$ & $16 \%$ & $43 \%$ \\
\hline OOPs as \% of CHE & $77 \%$ & $73 \%$ & $50 \%$ \\
\hline Other private health expenditure as \% of CHE & - & $3 \%$ & $6 \%$ \\
External health expenditure as \% of CHE & $9 \%$ & $8 \%$ & $1 \%$ \\
\hline Government health expenditure in Int\$ & 39 & 15 & 211 \\
\hline OOPs in Int\$ & 209 & 65 & 246 \\
\hline
\end{tabular}

$\mathrm{CHE}=$ current health expenditure, $\mathrm{GDP}=$ gross domestic product, $\mathrm{OOP} s=$ out of pocket payment, Int $\$=$ international dollars 